\title{
Association of Mothers' Pediatric Tuberculosis Knowledge and Attitudes with Health Seeking Practices in Kapsabet Referral Hospital, Nandi County, Kenya
}

\author{
Caroline Chepchirchir $^{*} \quad$ Dorothy A. Onjwa Onyango ${ }^{2} \quad$ Jackie Kpeinzeh Obey $^{3}$ \\ 1.Department of Public Health, University of Eastern Africa- Baraton, P.O Box 2500-30100, Eldoret, Kenya \\ 2.Department of Tourism and Hospitality Management, Jaramogi Oginga Odinga University of Science and \\ Technology, P.O Box 210-40601, Bondo, Kenya \\ 3.Department of Medical Laboratory Sciences, University of Eastern Africa-Baraton, P.O Box 2500-30100, \\ Eldoret, Kenya
}

\begin{abstract}
Tuberculosis (TB) is in the top rank of causes of pediatric morbidity and mortality. In 2017, approximately 1 million children were infected with the disease and 230,000 died. In Kenya, tuberculosis is number 4 on the causes of death with $6.3 \%$ of total deaths. Nandi County is one of the counties affected with Kapsabet Referral Hospital having a substantial number of cases for ages 0-14 years. The objective of the study was to assess the association of mothers' pediatric tuberculosis knowledge and attitudes with health seeking practices in Kapsabet Referral Hospital, Nandi County, Kenya. A cross-sectional research design was used to do the study and data collected using Knowledge, Attitudes and Practices (KAP) questionnaires based on World Health Organization (WHO) guidelines. Mothers attending Maternal Child Health $(\mathrm{MCH})$ clinic having children aged 0-14 years were the target population. Purposive and systematic random sampling were employed and sample calculated using Rao soft online calculator. SPSS version 25.0 was used for analysis that is, descriptive statistics (frequency distribution tables, Pearson chi-square test, odds ratio) and multinomial logistic regression. Results were reported as statistically significant if p-values $<0.05$. Results showed that mothers with children more than 2 (adj OR, 1.18; $95 \%$ CI, 0.69 to 2.05 ) and those with regular income (adj OR, 1.08; 95\% CI, 0.67 to 1.72 ) were more likely to have good knowledge. Those with higher levels of education (adj OR, 1.19; 95\% CI, 0.75 to 1.88), Christians (adj OR, 3.16; 95\% CI, 0.84 to 11.88), and those with regular income (adj OR, 1.08; 95\% CI, 0.67 to 1.72 ) were more likely to have positive attitudes. Most respondents $343(97.2 \%)$ would seek health care in a health facility. Employment (adj OR, 0.55, 95\% CI: 0.32-0.93, P value $<0.05$ ) was statistically significant to overall mothers' knowledge on pediatric TB. Age of mothers (adj OR: 0.70, 95\% CI: 0.43-1.12, P value $<0.05$ ) and number of children (adj OR, 0.57, 95\% CI: 0.32-0.99, P value $<0.05$ ) were statistically significant to overall pediatric TB attitudes of respondents. While Education ( $\mathrm{P}$ value $<0.05)$ was statistically significant to overall health seeking practices. Those with good knowledge (OR: 1.83 , 95\% CI: $0.16-20.48)$ and positive attitudes (OR: 1.22 , 95\% CI: 0.11-13.65) were more likely to seek health care in a health facility as compared to visiting a pharmacy or a traditional healer. Generally, respondents had inadequate knowledge, positive attitudes and good health seeking practices towards pediatric TB. There was an association of knowledge and attitudes with health seeking practices. Therefore, regular pediatric TB education is recommended at MCH, Kapsabet Referral Hospital, Nandi County, Kenya.
\end{abstract}

Keywords: Pediatric tuberculosis, Knowledge, Attitudes, Health seeking practice, Kenya, Nandi County, Kapsabet Referral Hospital

DOI: $10.7176 / \mathrm{JHMN} / 77-08$

Publication date:July $31^{\text {st }} 2020$

\section{Introduction}

TB is among the major public health issues in the World. In the 2030 Sustainable Development Goals (SDGs) there is a global target to end TB epidemic. End TB Strategy also has a goal to reduce TB incidence by $80 \%$ and mortality rate by $90 \%$. According to WHO, childhood TB is common in high endemic regions which includes Kenya. Annually, the number of children infected with TB is 550,000 at minimal. $70 \%-80 \%$ have pulmonary TB while the rest have extrapulmonary TB. $15 \%$ of deaths as a result of the disease was covered by children 15 years and under (World Health Organization, 2018).

As per Kenyan Tuberculosis Prevalence Survey 2015-2016, TB prevalence in the country was estimated to be 558 rates per 100,000 population. That means 138,105 incident cases annually. Causes of death by region showed that tuberculosis led to 714 deaths in north rift region in 2012 ("ECONOMIC SURVEY 2013," 2017). Percentage of total TB cases in Kenya represented by children between 0 and 14 years of age is above $11 \%$ (National Tuberculosis, Leprosy and Lung Disease Program, 2017).

Nandi county is one of the counties affected with the disease. The prevalence rate as of 2012 was 81 cases per 100,000 people while the incidence rate was 40 cases per 100,000 people (National Tuberculosis, Leprosy and 
Lung Disease Program, 2017). Data from TIBU database for Nandi county, shows pediatric TB prevalence with an annual average of $8 \%$ from 2014 to 2019. In Kapsabet Referral Hospital, there is a substantial number of cases for ages 0-14 years. In 2017 for example, there were 23 reported cases.

There is limited information on knowledge, attitude and health seeking practices of communities towards pediatric TB in the study area. Therefore, this study was conducted in Kapsabet Referral Hospital, Nandi County, Kenya to assess the association of mothers' pediatric TB knowledge and attitudes with health seeking practices.

\section{Methodology}

\subsection{Study Area}

The study area was Kapsabet Referral Hospital, a Ministry of Health hospital located in Kapsabet Town in Emgwen Constituency, Nandi County. It is found along Eldoret - Kisumu Highway. As per 2009 census, Kapsabet has a total population of 86,803 residents. Most of them belonging to Nandi section of Kalenjin ethnic group. Kapsabet being the headquarters of Nandi County is the most populated place.

Kapsabet Referral Hospital provides both inpatient and outpatient care. It is equipped with a Maternal and Child Health Clinic, TB clinic, maternity ward and a Comprehensive Care Center (CCC). They also offer Voluntary Counselling and Testing (VCT) and social services.

\subsection{Population and Sampling Techniques}

Purposive sampling was used to select the hospital and clinic. Kapsabet Referral Hospital was chosen because it is a referral hospital which means other health centers refer their patients there therefore, a high likelihood of many people visiting. $\mathrm{MCH}$ ) was chosen because the study participants were mothers who are more likely to bring their children to clinic.

Systematic random sampling was used to select mothers to participate in the study while simple random sampling was used to get the number to represent the first respondent.

\subsection{Sample Frame}

The sampling frame in this study was the list of all mothers that always visit $\mathrm{MCH}$ in Kapsabet Referral Hospital.

\subsection{Sample Size Determination}

Rao soft sample size calculator was used to get the sample size. A confidence interval of $95 \%$, a margin error of $5 \%$ and a response distribution of $50 \%$ was used. Using the average number of mothers visiting the clinic per month that is 3,000 , the sample size was 341 respondents. During the study, more mothers participated and the extra number was to cater for any errors that might be discovered on the questionnaires during analysis. After cleaning of the data, 355 questionnaires were used in the analysis.

\subsection{Inclusion and Exclusion Criteria}

Mothers visiting MCH were eligible for the study. They had children between ages 0-14 and were the biological mothers to those they were bringing for clinical visit. They were present on the day of the study and voluntarily willed to participate by giving their consent. They also were not mentally ill. Mothers not present on the day of study and those not willing to participate were excluded.

\subsection{Data Gathering Procedure}

Data collection was carried out once those in authority had been notified. During data collection, questionnaires were administered to qualified mothers. Systematic random sampling was used to select mothers to participate in the study. The average total number of mothers $(3,000)$ was divided by the sample size $(341)$ to get the interval (9). Simple random sampling was then used to get the number (3) to represent the first respondent. The number had to be between 1 and the interval calculated. Mothers involved were sitting on the line waiting to be attended to. In case the recruited mother did not consent, the next one was included.

Data collection was done face to face by research assistants recruited from the local community based on their academic qualifications, research experience and familiarity to the study area. They were then trained on the research process and familiarized themselves with questions in the questionnaire. At the end of the day after data collection, questionnaires were counter checked by the principal investigator.

\subsection{Statistical Treatment of Data}

SPSS version 25.0 was used for analysis. General and demographic factors and mothers' level of knowledge, attitudes and health seeking practices were summarized using frequency distribution tables. Pearson chi-square test was used to calculate significance of confounding factors on overall pediatric TB knowledge, attitudes and health seeking practices. It was also used to evaluate statistical significance of associations of independent variables with dependent variable. Odds ratio (OR) gave the strength of association between confounding factors 
and knowledge, attitudes and health seeking practices. It was also used to determine the association of independent variables with outcome variables. Findings were considered to be statistically significant if the p-values $<0.05$. Multinomial logistic regression was used to explore the association of overall mothers' knowledge and attitudes with health seeking practices towards pediatric tuberculosis.

\subsection{Ethical Considerations}

In consideration of protection of individual and institutions' rights, research ethics was required. The researcher required ethical clearance from University of Eastern Africa, Baraton (UEAB) Research Ethics Committee, National Commission for Science, Technology and Innovation (NACOSTI), Nandi County and Kapsabet Referral Hospital. There was an explanation of the study to participants in order for them to make decision on giving consent and participating in the research. Voluntary participation was allowed and participants were free to drop out of the study at will. There were no names of participants on the questionnaires and confidentiality of the results was ensured.

\section{Results}

\subsection{Demographic Profile of Mothers}

Demographic profile of mothers was summarized using frequency distribution table (Table 1). Some variables: age, number of children, education, marital status, religion and family income had to be recoded as part of the analysis process. Among the 355 study participants, $264(74.4 \%)$ were under or equal to 30 years, $292(82.3 \%)$ had children ages of 0-2 years, most of the mothers 254 (71.5\%) had achieved high school and above levels of education, $250(70.6 \%)$ were married, $343(96.6 \%)$ were Christians, $283(79.9 \%)$ were employed with $256(72.5 \%)$ having an irregular or no defined source of income and $61(17.8 \%)$ had a family history of TB.

Table 1. Demographic Profile of Mothers in Kapsabet Referral Hospital, Nandi County, Kenya

\begin{tabular}{lll}
\hline & Characteristic & Total number N (\%) interviewed \\
\hline Age & $<=30$ & $264(74.4)$ \\
Children & $>=31$ & $91(25.6)$ \\
\multirow{2}{*}{ Education } & $0-2$ & $292(82.3)$ \\
& $3-6$ & $63(17.7)$ \\
Marital Status & No school/Primary school & $101(28.5)$ \\
& High school/Higher education & $254(71.5)$ \\
Religion & Married & $250(70.6)$ \\
& Others & $104(29.4)$ \\
Employment & Christian & $343(96.6)$ \\
& Others & $12(3.4)$ \\
Family Income & Yes & $283(79.7)$ \\
& No & $72(20.3)$ \\
Family history of TB & Regular & $97(27.5)$ \\
& Irregular/No income & $256(72.5)$ \\
& Yes & $61(17.8)$ \\
\end{tabular}

\subsection{Mothers' Knowledge on Pediatric TB}

Mothers' knowledge was assessed using 9 questions. After data entry, a composite score was calculated and dichotomized. Values above or equal to the mean (0.38) were coded as 1 and represented good knowledge while values below 0.38 were coded as 0 and represented poor knowledge.

Majority of mothers 208 (59.6\%) were not well informed on pediatric TB. Radio 206 (58\%) was found to be an effective source of information followed by health workers 159 (44.8\%) in the study area. On signs and symptoms of pediatric TB, most $240(67.6 \%)$ of the respondents answered YES to coughing that lasts longer than 3 weeks. Other symptoms mentioned were coughing up blood 209 (58.9\%) and chest pain 219 (61.7\%). Majority $319(89.9 \%)$, knew that pediatric TB is transmitted through the air when one coughs or sneezes (Table 2).

Most of the mothers $259(73.0 \%)$ answered covering of mouth and nose when coughing and sneezing as a means of preventing pediatric TB. Some 124 (34.9\%) said vaccination. A higher proportion of mothers 338 (95.2\%) knew that pediatric TB can be cured with most of them $329(92.7 \%)$ being aware that there are specific drugs provided by health facilities for treatment of TB (Table 2).

Overall knowledge mean score was 0.38 . Mothers with children more than 2 (adjusted OR, 1.18; $95 \%$ CI, 0.69 to 2.05 ) and those with regular income (adjusted OR, 1.08; 95\% CI, 0.67 to 1.72 ) were more likely to have good knowledge. Employment (adjusted OR, 0.55, 95\% CI: 0.32-0.93, P value < 0.05 ) was statistically significant to overall mothers' knowledge on pediatric TB (Table 3 ). 
Table 2. Mothers' Knowledge on Pediatric TB in Kapsabet Referral Hospital, Nandi County, Kenya

\begin{tabular}{|c|c|c|}
\hline Knowledge variables & Yes, N (\%) & No, $\mathbf{N}(\%)$ \\
\hline \multicolumn{3}{|l|}{ Pediatric TB Symptoms } \\
\hline Loss of appetite & $126(35.5)$ & $229(64.5)$ \\
\hline Night sweats & $153(43.1)$ & $202(56.9)$ \\
\hline Cough that lasts longer than 3 weeks & $240(67.6)$ & $115(32.4)$ \\
\hline Coughing up blood & $209(58.9)$ & $146(41.1)$ \\
\hline Severe headache & $123(34.6)$ & $232(65.4)$ \\
\hline Nausea & $110(31.0)$ & $245(69.0)$ \\
\hline Weight loss & $198(55.8)$ & $157(44.2)$ \\
\hline Fever & $165(46.5)$ & $190(53.5)$ \\
\hline Chills & $110(31.0)$ & $245(69.0)$ \\
\hline Chest pain & $219(61.7)$ & $136(38.3)$ \\
\hline Shortness of breadth & $183(51.5)$ & $172(48.5)$ \\
\hline Ongoing fatigue & $152(42.8)$ & $203(57.2)$ \\
\hline Do not know & $33(9.3)$ & $322(90.7)$ \\
\hline \multicolumn{3}{|l|}{ Pediatric TB Transmission } \\
\hline Through handshakes & $9(2.5)$ & $346(97.5)$ \\
\hline Through the air when one coughs/sneezes & $319(89.9)$ & $36(10.1)$ \\
\hline Through sharing dishes & $42(11.8)$ & $313(88.2)$ \\
\hline Through touching items in public places & $15(4.2)$ & $340(95.8)$ \\
\hline Do not know & $17(4.8)$ & $338(95.2)$ \\
\hline \multicolumn{3}{|l|}{ Pediatric TB Prevention } \\
\hline Avoid shaking hands & $7(2.0)$ & $348(98.0)$ \\
\hline Covering mouth and nose when coughing/sneezing & $259(73.0)$ & $96(27.0)$ \\
\hline Avoid sharing dishes & $37(10.4)$ & $318(89.6)$ \\
\hline Washing hands after touching items in public places & $34(9.6)$ & $321(90.4)$ \\
\hline Closing windows at home & $6(1.7)$ & $349(98.3)$ \\
\hline Through good nutrition & $24(6.8)$ & $331(93.2)$ \\
\hline By praying & $11(3.1)$ & $344(96.9)$ \\
\hline Vaccination & $124(34.9)$ & $231(65.1)$ \\
\hline Do not know & $13(3.7)$ & $342(96.3)$ \\
\hline Can Pediatric TB be cured? & $338(95.2)$ & $17(4.8)$ \\
\hline \multicolumn{3}{|l|}{ Curing Pediatric TB } \\
\hline Herbal remedies & $10(2.8)$ & $345(97.2)$ \\
\hline Home rest without medicine & $4(1.1)$ & $351(98.9)$ \\
\hline Praying & & $355(100.0)$ \\
\hline Specific drugs given by health center & $329(92.7)$ & $26(7.3)$ \\
\hline Do not know & $9(2.5)$ & $349(97.5)$ \\
\hline Are you well informed about pediatric TB? & $141(40.4)$ & $208(59.6)$ \\
\hline \multicolumn{3}{|l|}{ Effective sources of information on pediatric TB } \\
\hline Radio & $206(58.0)$ & $149(42.0)$ \\
\hline Television & $134(37.7)$ & $221(62.3)$ \\
\hline Brochures, posters and printed materials & $88(24.8)$ & $267(75.2)$ \\
\hline Health workers & $159(44.8)$ & $196(55.2)$ \\
\hline Family, friends, neighbors and colleagues & $45(12.7)$ & $310(87.3)$ \\
\hline Religious leaders & $20(5.6)$ & $335(94.4)$ \\
\hline Teachers & $25(7.0)$ & $330(93.0)$ \\
\hline
\end{tabular}


Table 3. Mothers' Overall Pediatric TB Knowledge in Kapsabet Referral Hospital, Nandi County, Kenya

\begin{tabular}{|c|c|c|c|c|c|c|c|}
\hline \multicolumn{2}{|c|}{ Confounders } & \multicolumn{6}{|c|}{ Mothers' overall pediatric TB knowledge } \\
\hline & & \multirow{2}{*}{$\begin{array}{l}\begin{array}{l}\text { Total, } \\
\text { Interviewed }\end{array} \\
264(74.4) \\
\end{array}$} & $\begin{array}{l}\text { NGood } \\
\text { Knowledge,N } \\
(\%)\end{array}$ & $\begin{array}{l}\text { Poor } \\
\text { Knowledge,N } \\
(\%)\end{array}$ & COR $(95 \%$ CL) & \multirow{3}{*}{$\begin{array}{l}\text { AOR }(95 \% \mathrm{CL}) \\
0.61(0.38-0.98)\end{array}$} & P-Value \\
\hline \multirow[t]{2}{*}{ Age } & $<=30$ years & & $118(44.7)$ & $146(55.3)$ & $0.66(0.41-1.07)$ & & 0.091 \\
\hline & $>=31$ years & $91(25.6)$ & $52(57.1)$ & $39(42.9)$ & & & \\
\hline \multirow[t]{2}{*}{ Children } & $0-2$ children & $292(82.3)$ & $142(48.6)$ & $150(51.4)$ & $1.46(0.84-2.54)$ & $1.18(0.69-2.05)$ & 0.180 \\
\hline & 3-6 children & $63(17.7)$ & $28(44.4)$ & $35(55.6)$ & & & \\
\hline \multirow[t]{4}{*}{ Education } & No School/Primary & $y 101(28.5)$ & $46(45.5)$ & $55(54.5)$ & $0.78(0.49-1.23)$ & $0.88(0.55-1.39)$ & 0.066 \\
\hline & School & $254(71.5)$ & $124(48.8)$ & $130(51.2)$ & & & \\
\hline & High Schoo & & & & & & \\
\hline & /Higher Education & & & & & & \\
\hline \multirow[t]{2}{*}{ Marital Status } & Married & $250(70.6)$ & $114(45.6)$ & $136(54.4)$ & $0.65(0.40-1.03)$ & $0.72(0.45-1.14)$ & 0.278 \\
\hline & Others & $104(29.4)$ & $56(53.8)$ & $48(46.2)$ & & & \\
\hline \multirow[t]{2}{*}{ Religion } & Christian & 343 (96.6) & $164(47.8)$ & $179(52.2)$ & $1.83(0.54-6.20)$ & $0.92(0.29-2.90)$ & 0.323 \\
\hline & Other & $12(3.4)$ & $6(50.0)$ & $6(50.0)$ & & & \\
\hline \multirow[t]{2}{*}{ Employment } & No & $72(20.3)$ & $127(44.9)$ & $156(55.1)$ & $0.43(0.25-0.73)$ & $0.55(0.32-0.93)$ & $.002^{*}$ \\
\hline & Yes & $283(79.7)$ & $43(59.7)$ & $29(40.3)$ & & & \\
\hline \multirow[t]{2}{*}{ Income } & Regular & $97(27.5)$ & $48(49.5)$ & $49(50.5)$ & $1.05(0.66-1.67)$ & $1.08(0.67-1.72)$ & 0.842 \\
\hline & $\begin{array}{l}\text { Irregular/No } \\
\text { defined income }\end{array}$ & $256(72.5)$ & $122(47.7)$ & $134(52.3)$ & & & \\
\hline \multirow{2}{*}{\multicolumn{2}{|c|}{$\begin{array}{l}\text { Has any familyNo } \\
\text { member ever hadYes } \\
\text { TB }\end{array}$}} & $281(82.2)$ & $127(45.2)$ & $154954.8)$ & $0.60(0.35-1.06)$ & $0.57(0.33-1.00)$ & 0.075 \\
\hline & & $61(17.8)$ & $36(59.0)$ & $25(41.0)$ & & & \\
\hline
\end{tabular}

Chi-Square test (alpha $=0.05), \mathrm{P}<0.05^{*}$

\subsection{Mothers' Attitudes Towards Pediatric TB}

Attitudes of respondents was assessed using 5 questions. A YES answer was coded as 1 while a No answer coded as 0 . After data entry, a composite score was calculated and dichotomized. Values equal to or above the mean $(0.42)$ were coded as 1 and represented positive attitudes while values less than 0.42 were coded as 0 representing negative attitudes.

Mothers' attitudes towards pediatric TB is summarized in (Table 4).More than half 335 (94.4\%) of the respondents said that pediatric TB can infect anybody. A majority of the respondents 237 (73.8\%) had the opinion that their children can get TB while 84 (26.2) said "no". When asked "what would be your reaction if you found out your child has TB?" most of them 186 (52.4\%) answered "fear" while others said "sadness". A bigger percentage of mothers $334(96.3 \%)$ wished they could get more information on pediatric TB. What worried most of the mothers was death as a result of being infected by pediatric TB.

Overall attitude mean score was 0.42 . Mothers with higher levels of education (adjusted OR, 1.19; 95\% CI, 0.75 to 1.88 ), Christians (adjusted OR, 3.16; 95\% CI, 0.84 to 11.88), and those with regular income (adjusted OR, 1.08; $95 \%$ CI, 0.67 to 1.72 ) were more likely to have positive attitudes. Age of mothers (adjusted OR: 0.70, 95\% CI: $0.43-1.12$, P value $<0.05$ ) and number of children (adjusted OR, 0.57, 95\% CI: 0.32-0.99, P value $<0.05$ ) were statistically significant to the overall pediatric TB attitudes of respondents (Table 5). 
Table 4. Mothers' Attitudes Towards Pediatric TB in Kapsabet Referral Hospital, Nandi County, Kenya

\begin{tabular}{|c|c|c|}
\hline Attitude variables & Yes, N (\%) & No, $\mathbf{N}(\%)$ \\
\hline \multicolumn{3}{|l|}{ In your opinion who can be infected with TB? } \\
\hline Anybody & $335(94.4)$ & $20(5.6)$ \\
\hline Only poor people & $4(1.1)$ & $351(98.8)$ \\
\hline Only homeless people & $1(0.3)$ & $354(99.7)$ \\
\hline Only alcoholics & $2(0.6)$ & $353(99.4)$ \\
\hline Only drug users & $2(0.6)$ & $353(99.4)$ \\
\hline Only people living with HIV & $7(2.0)$ & $348(98.0)$ \\
\hline Only people who have been in prison & $3(0.8)$ & $352(99.2)$ \\
\hline Do you think your child can get TB? & $237(73.8)$ & $84(26.2)$ \\
\hline \multicolumn{3}{|l|}{ What would be your reaction if you found out your child has TB? } \\
\hline Fear & $186(52.4)$ & $169(47.6)$ \\
\hline Surprise & $28(7.9)$ & $327(92.1)$ \\
\hline Shame & $6(1.7)$ & $349(98.3)$ \\
\hline Embarrassment & $5(1.4)$ & $350(98.6)$ \\
\hline Sadness & $78(22.3)$ & $276(77.7)$ \\
\hline Hopelessness & $8(2.3)$ & $347(97.7)$ \\
\hline Do you wish you could get more information about pediatric TB? & $334(96.3)$ & $13(3.7)$ \\
\hline
\end{tabular}

Table 5. Mothers' Overall Attitudes Towards Pediatric TB in Kapsabet Referral Hospital, Nandi County, Kenya

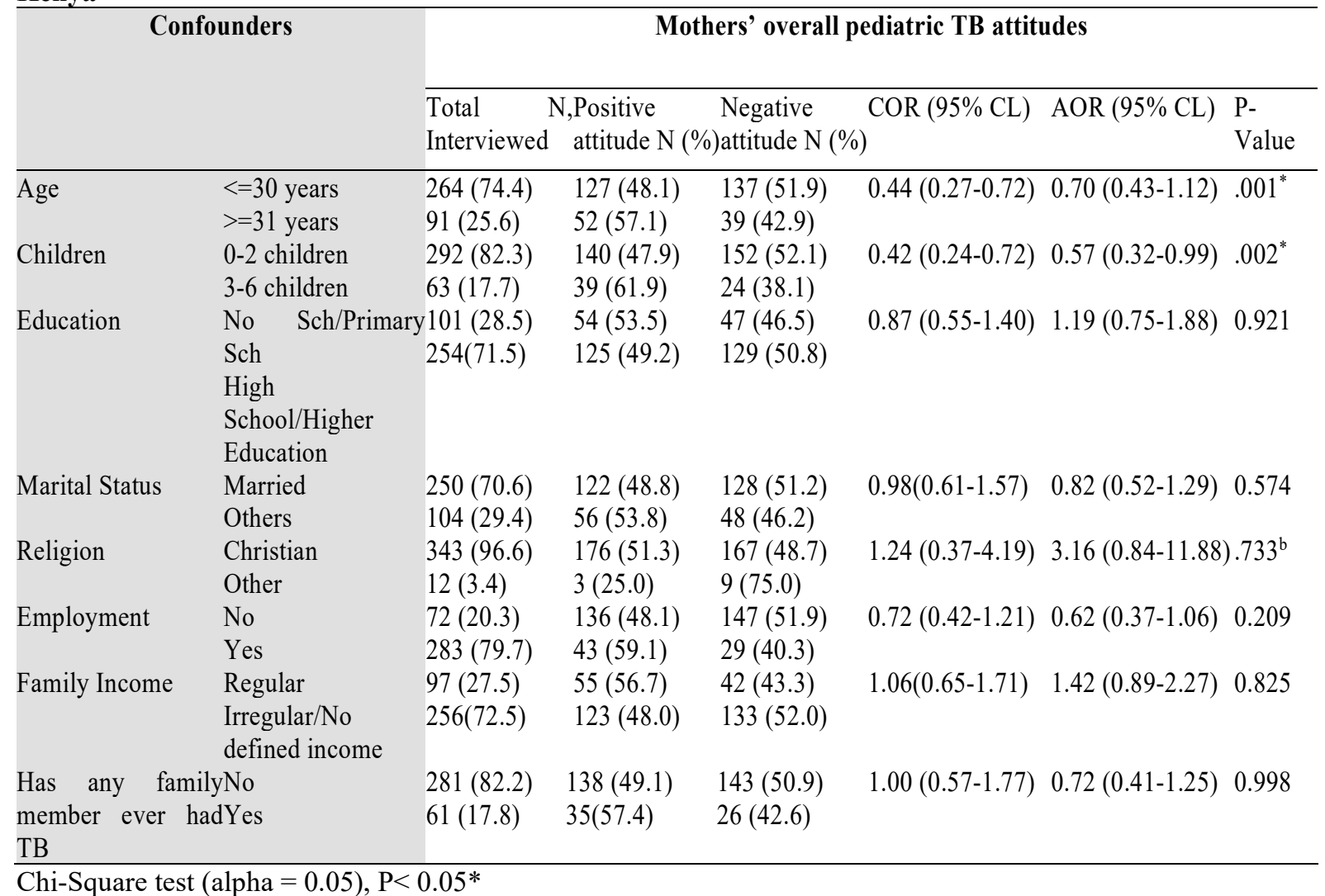

\subsection{Health Seeking Practices Towards Pediatric TB}

Health seeking practices were assessed using 3 questions. After data entry, a composite score was calculated and dichotomized. Values equal to or above the mean (0.33) were coded as 1 and represented good practice while values less than 0.33 were coded as 0 representing poor practice.

The findings of this study showed that as far as health seeking practice is concerned, most of the respondents $343(97.2 \%)$ would go to a health facility if they found out that their children had signs and symptoms of TB (Figure 1). Looking at (Figure 2), a majority 242 (68.2\%) would visit a health care center as soon as they realized that their children had symptoms of TB while others $93(26.3 \%)$ would wait for 3-4 weeks. Those that would not go to a health facility $5(1.4 \%)$ said that they were not sure where to go in the health facility $43(12.1 \%)$ while 
some $52(14.6 \%)$ had difficulties with transportation or distance to clinic.

Overall, those that answered YES to health facility as a place to seek health care were considered as having good health seeking practice while those that said pharmacy or traditional healer were considered as having poor practice. Education (P value $<0.05$ ) was statistically significant to overall health seeking practices of mothers at Kapsabet Referral Hospital, Nandi County, Kenya (Table 6).

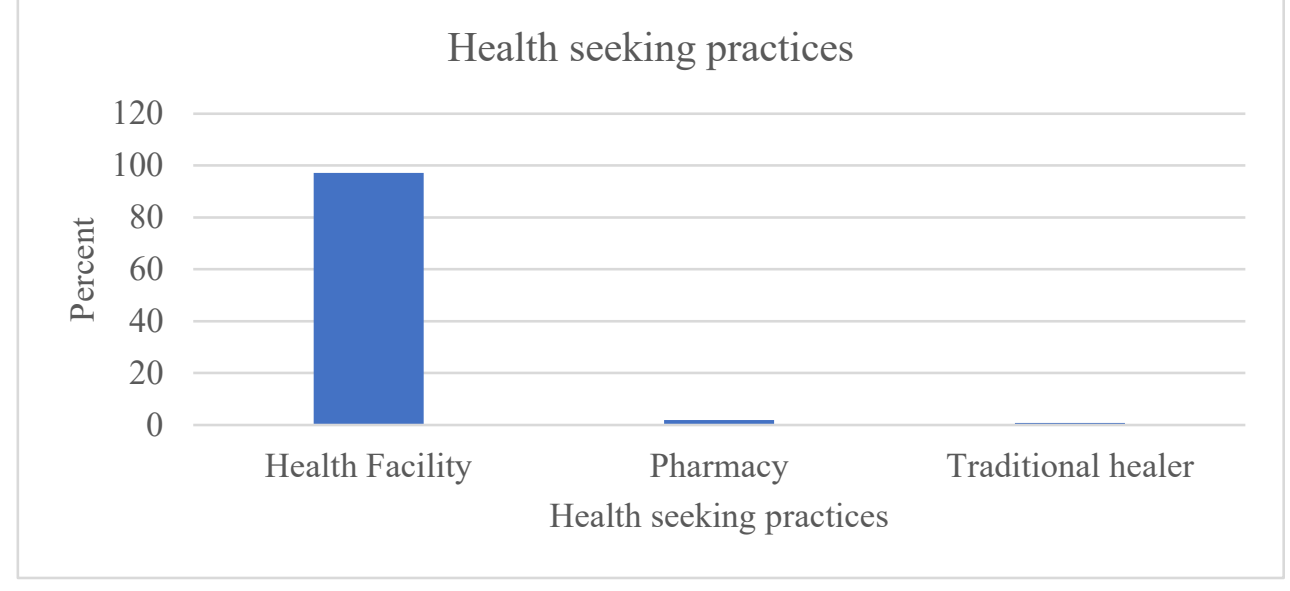

Figure 1. Health Seeking Practices

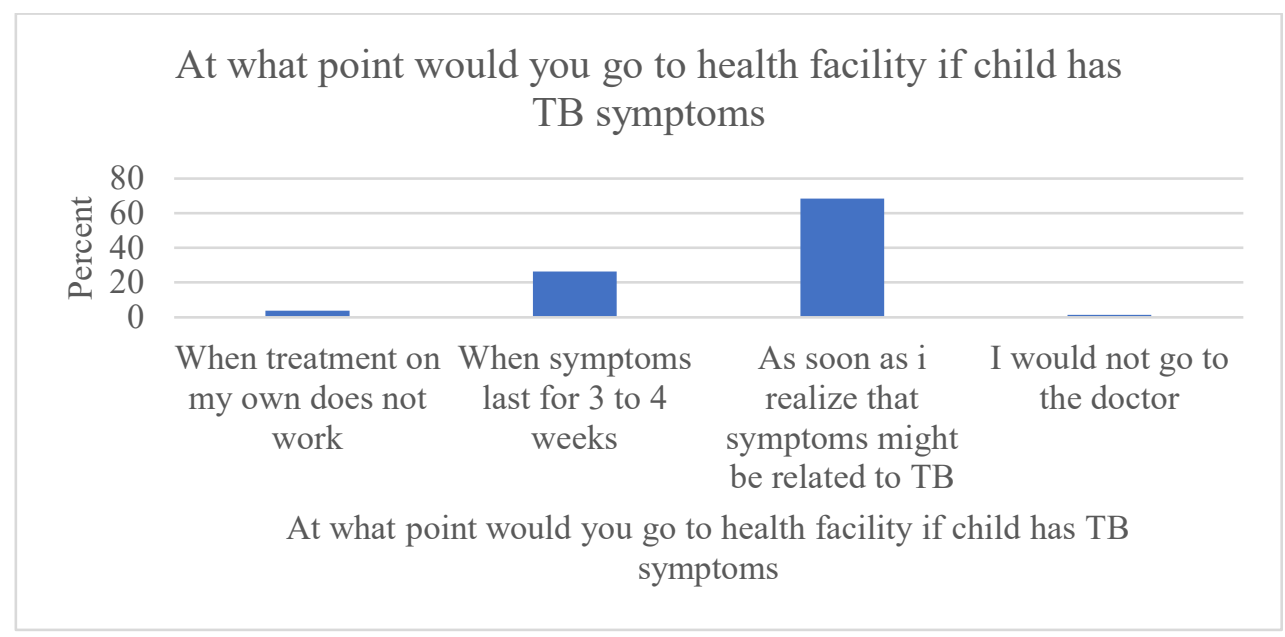

Figure 2. At what point would you go to a Health Facility if Child has TB Symptoms 
Table 6. Mothers' Overall Pediatric TB Health Seeking Practices in Kapsabet Referral Hospital, Nandi County, Kenya

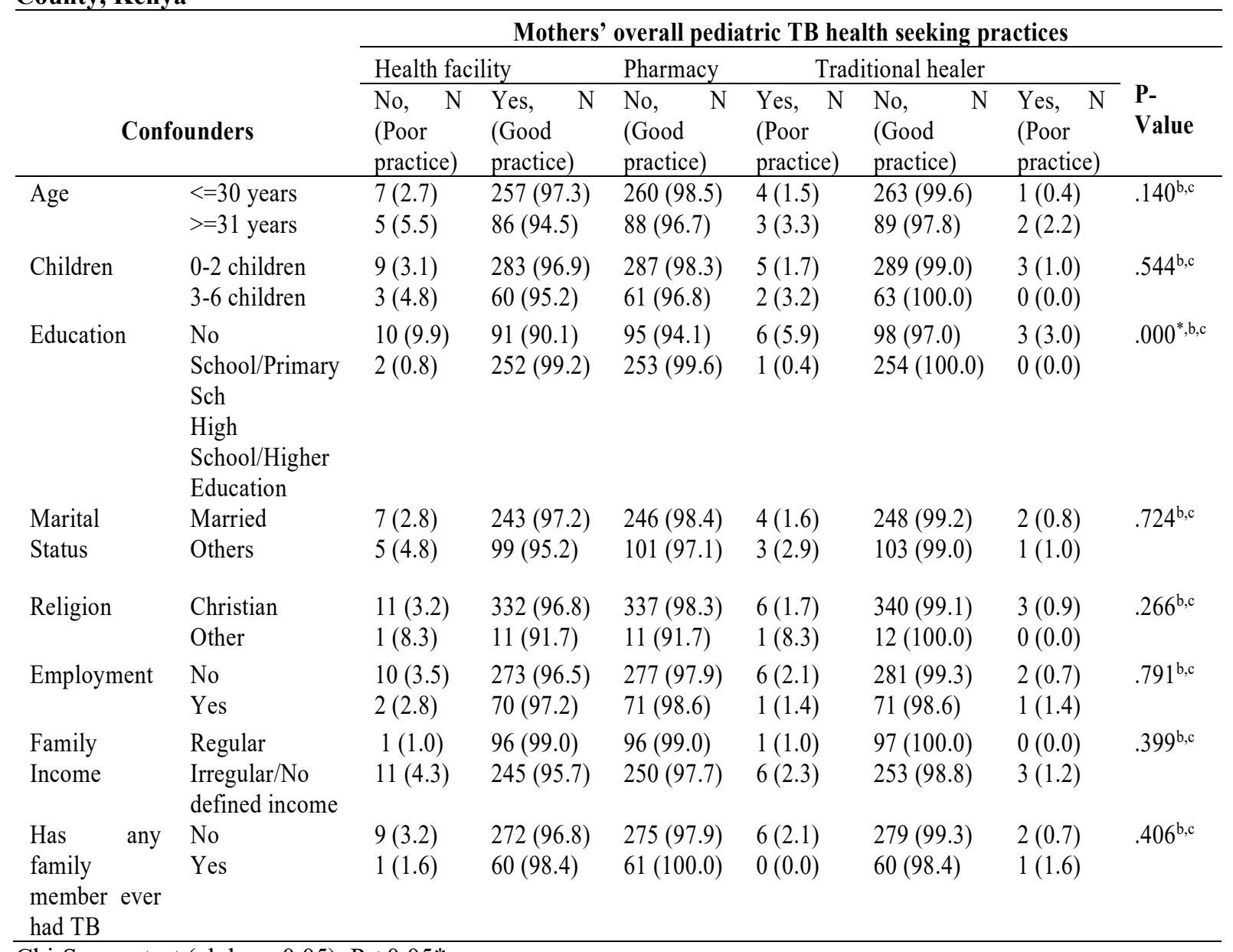

Chi-Square test (alpha $=0.05), \mathrm{P}<0.05^{*}$

\subsection{Association of Mothers' Pediatric TB Knowledge with Health Seeking Practices}

The association of mothers' pediatric TB knowledge with health seeking practices was assessed using odds ratio (OR) with $95 \%$ confidence interval. The likelihood of mothers with good knowledge as compared to poor knowledge seeking health care for their children in a health facility, a pharmacy or from a traditional healer was assessed. OR $>1$ indicated a higher probability of a health seeking practice occurring while $\mathrm{OR}<1$ indicated a lower probability. The associations were reported as statistically significant if the p-values $<0.05$.

The findings are presented in (Table 7). Mothers who knew cough that lasts longer than 3 weeks (OR: 2.15, 95\% CI: 0.68-6.81), weight loss (OR: 2.60, 95\% CI: 0.77-8.81), fever (OR: 2.69, 95\% CI: 0.72-10.09), chest pain (OR: 2.32, 95\% CI: 0.72-7.47), shortness of breath (OR: 2.18, 95\% CI: 0.65-7.39) and ongoing fatigue (OR: 2.30, 95\% CI: $0.61-8.66)$ were signs and symptoms of pediatric TB were more likely to take their children to a health facility. Those that knew pediatric TB was transmitted through the air when one coughs or sneezes (OR: 3.13, 95\% CI: 0.81-12.14) were also more likely to take their children to a health facility.

As part of pediatric TB prevention respondents that answered covering mouth and nose when coughing or sneezing (OR: 1.98, 95\% CI: 0.61-6.39) and vaccination (OR: 2.76, 95\% CI: 0.60-12.80) were more likely to go to a health facility. Also, mothers who knew there are specific drugs available in health centers for treatment of TB (OR: 7.30, 95\% CI: 2.04-26.12, P value < 0.05) were significantly more likely to take their children to a health facility when infected with TB. Individuals that said radio was the most effective source of information on pediatric TB (OR: $1.98,95 \%$ CI: 0.62-6.37) and those that were well informed on pediatric TB (OR: $1.60,95 \%$ CI: 0.41 6.30) were more likely to visit a health facility compared to a pharmacy or a traditional healer for treatment.

Considering good and poor knowledge on pediatric TB, mothers with good knowledge (OR: 1.83, 95\% CI: 0.16-20.48) were more likely to seek health care in a health facility as compared to visiting a pharmacy or a traditional healer. 
Table 7. Associations of Mothers' Pediatric TB Knowledge with Health Seeking Practices in Kapsabet Referral Hospital, Nandi County, Kenya

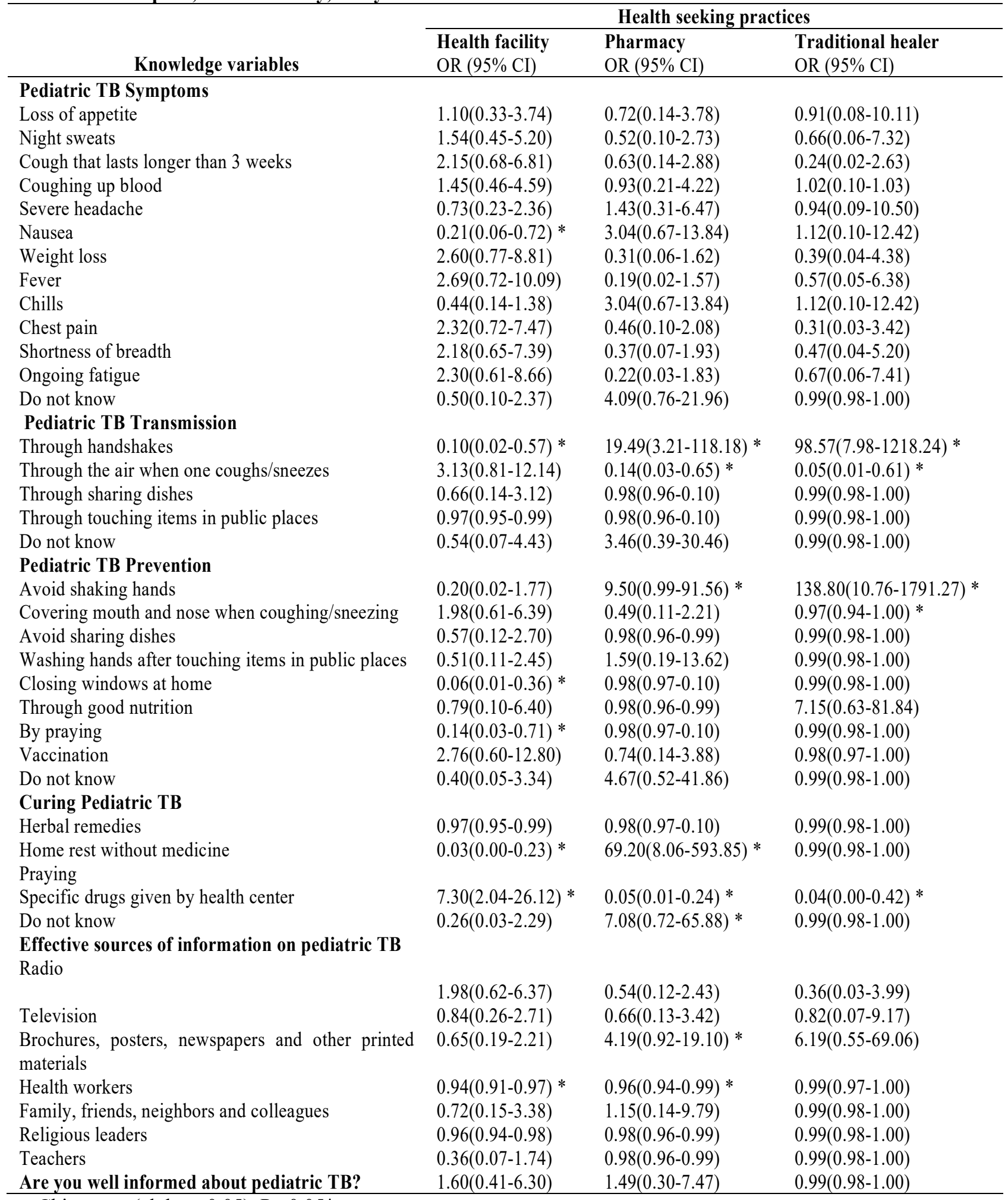

Chi-square (alpha $=0.05), \mathrm{P}<0.05^{*}$

\subsection{Association of Mothers' Attitudes Towards Pediatric TB with Health Seeking Practices}

The association of mothers' pediatric TB attitudes with health seeking practices was assessed using odds ratio with $95 \%$ confidence interval. The likelihood of mothers with positive attitudes compared to negative attitudes seeking health care for their children in a health facility, a pharmacy or from a traditional healer was assessed. OR $>1$ indicated a higher probability of a health seeking practice occurring while $\mathrm{OR}<1$ indicated a lower probability. 
The associations were reported as statistically significant if the $\mathrm{p}$-values $<0.05$.

Association of mothers' pediatric TB attitudes with health seeking practices is summarized in (Table 8). On the question "in your opinion who can be infected with TB?" mothers that answered "anybody" (OR: 15.62, 95\% CI: 4.44-55.00, P-Value < 0.05) were significantly more likely to seek health care in a health facility as compared to going to a pharmacy or a traditional healer. Those that thought their children could get TB (OR: $2.94,95 \%$ CI: 0.83-10.41) and the ones that would experience fear if they found out that their children had TB (OR: 2.26, 95\% CI: 0.67-7.65) were also more likely to visit a health facility if their children got infected. Respondents that wished they could get more information on pediatric TB (OR: 10.83, 95\% CI: 2.54-46.20, P-Value < 0.05) were significantly more likely to seek health care in a health facility and not a pharmacy or from a traditional healer. Considering positive and negative attitudes towards pediatric TB, mothers with positive attitudes (OR: 1.22, 95\% CI: $0.11-13.65)$ were more likely to seek health care in a health facility as compared to a pharmacy or from a traditional healer.

Table 8. Associations of Mothers' Pediatric TB Attitudes with Health Seeking Practices in Kapsabet Referral Hospital, Nandi County, Kenya

\begin{tabular}{|c|c|c|c|}
\hline \multirow[t]{2}{*}{ Attitude variables } & \multicolumn{3}{|c|}{ Health seeking practices } \\
\hline & $\begin{array}{l}\text { Health facility } \\
\text { OR }(95 \% \mathrm{CI})\end{array}$ & $\begin{array}{l}\text { Pharmacy } \\
\text { OR }(95 \% \mathrm{CI})\end{array}$ & $\begin{array}{l}\text { Traditional } \\
\text { healer } \\
\text { OR }(95 \% \mathrm{CI})\end{array}$ \\
\hline $\begin{array}{l}\text { In your opinion who can be infected } \\
\text { with TB? } \\
\text { Anybody }\end{array}$ & $15.62(4.44-55.00) *$ & $0.07(0.14-0.33) *$ & $1.01(1.00-1.02)$ \\
\hline Only poor people & $0.02(0.01-0.05) *$ & $69.20(8.06-593.85) *$ & $0.99(0.98-1.00)$ \\
\hline Only homeless people & $0.03(0.02-0.06) *$ & $0.02(0.01-0.04) *$ & $0.99(0.98-1.00)$ \\
\hline Only alcoholics & $0.97(0.95-0.99)$ & $0.98(0.97-1.00)$ & $0.99(0.98-1.00)$ \\
\hline Only drug users & $0.97(0.95-0.99)$ & $0.98(0.97-1.00)$ & $0.99(0.98-1.00)$ \\
\hline Only people living with HIV & $0.97(0.95-0.99)$ & $0.98(0.97-1.00)$ & $0.99(0.98-1.00)$ \\
\hline Only people who have been in prison & $0.02(0.00-0.18) *$ & $0.98(0.97-1.00)$ & $0.99(0.98-1.00)$ \\
\hline Do you think your child can get TB? & $2.94(0.83-10.41)$ & $0.23(0.04-1.40)$ & $1.01(1.00-1.03)$ \\
\hline $\begin{array}{l}\text { What would be your reaction if you } \\
\text { found out your child has TB? }\end{array}$ & & & \\
\hline Fear & $2.26(0.67-7.65)$ & $0.36(0.07-1.86)$ & $0.92(0.96-1.00)$ \\
\hline Surprise & $0.94(0.12-7.56)$ & $1.98(0.23-17.06)$ & $0.99(0.98-1.00)$ \\
\hline Shame & $0.16(0.02-1.51)$ & $11.43(1.15-113.33) *$ & $0.99(0.98-1.00)$ \\
\hline Embarrassment & $0.97(0.95-0.99)$ & $0.98(0.97-1.00)$ & $0.99(0.98-1.00)$ \\
\hline Sadness & $0.56(0.16-1.91)$ & $0.58(0.07-4.86)$ & $1.04(1.00-1.09) *$ \\
\hline Hopelessness & $0.97(0.95-0.99)$ & $0.98(0.97-1.00)$ & $0.99(0.98-1.00)$ \\
\hline $\begin{array}{l}\text { Do you wish you could get more } \\
\text { information about pediatric TB? }\end{array}$ & $10.83(2.54-46.20) *$ & $0.04(0.01-0.21) *$ & $1.01(1.00-1.02)$ \\
\hline
\end{tabular}

Chi-square (alpha $=0.05), \mathrm{P}<0.05^{*}$

\section{Discussion}

This study was cross-sectional which might limit its generalization to the whole community. Despite that, it provides important insight on mothers' pediatric TB knowledge, attitudes and health seeking practices. It explores the association of mothers' pediatric TB knowledge and attitudes with health seeking practices in a country with a TB burden. Results from the study show that there was an association of independent variables with the dependent variable.

\subsection{Mothers Knowledge on Pediatric TB}

As per this study, most mothers were not well informed on pediatric TB. Overall knowledge mean score was 0.38 . This implies that the level of knowledge on pediatric TB in the study area is inadequate. Majority of them had basic knowledge on signs and symptoms, transmission, prevention and treatment of the disease. A survey done by Kenyan tuberculosis prevalence survey (Mungai, 2017), did not include data for 0-14 age group. This means pediatric TB has not been given much consideration in the country. Also, a study done in Tarlac City, Philippines showed that Directly Observed Treatment, short course (DOTs) program was available but it was only for the adult population and so this did not encourage pediatric treatments therefore poor knowledge (Bacay-Domingo and OngLim, 2009). If mothers are not well informed of the disease, they are not likely to associate their children's signs and symptoms with TB.

According to this study, coughing that lasts longer than three weeks and coughing blood were mentioned by most of the participants as signs and symptoms of pediatric TB. This correlates with a study done among Urban 
Nigerians which found out that coughing was the most common warning sign for TB followed by hemoptysis (Desalu et al., 2013). Apart from pediatric TB prevention by covering of mouth and nose when coughing and sneezing, vaccination was mentioned by a substantial percentage of mothers. A study done to find out how Bacille Calmette-Guerin (BCG) vaccine affects Mycobacterium tuberculosis in children showed that the vaccine can protect against infection (Roy et al., 2014).

The main source of information on pediatric TB according to mothers in the study area was radio and health workers. Most of them answered radio as the first place they heard about pediatric TB. Others were informed about the disease as they attended clinics in the health facility. This agrees with a research done in Tarlac City, Philippines, which showed that the major sources of information on TB were media and that people also visited locally available health centers and hospitals to ask for information (Bacay-Domingo and Ong-Lim, 2009). This means health workers and radio are successful means of disseminating information about pediatric TB. Television (TV) was mentioned by a few of the mothers as an effective source of information. Reason could be that most of them did not own televisions because of irregular and no defined sources of income.

In this study, most of the respondents knew that there are specific drugs available in health centers for treatment of TB. Majority of them also knew that treatment is provided free of charge. This must be the reason why a bigger percentage of mothers answered they would seek health care in a health facility if their children had signs and symptoms of TB. This agrees with a research done in Itang Special District, Gambella Region, South Western Ethiopia (Bati et al., 2013) where majority of study participants knew there existed modern drugs to treat and cure TB that infects the lungs.

Mothers with children more than 2 were more likely to have good knowledge on pediatric TB. The reason could be that mothers with more children have higher levels of experience in child care and may have encountered many disease symptoms that they can tell which are related to TB. Mothers with regular incomes were also more likely to have good knowledge which could explain why employment was statistically significant. They may visit health facilities regularly for physical exams and can afford to pay for diagnosis that is, $\mathrm{x}$-ray and laboratory tests which require money. They may also afford to own media products like radio and television where they can easily get information on pediatric TB.

\subsection{Mothers' Attitudes Towards Pediatric TB}

With reference to attitudes, it is clear that mothers in the study area knew TB can infect anybody. They were aware that their children are at risk of being infected with the disease. In addition to that, they would like to get more information on pediatric TB. This is a positive attitude which may influence their curiosity and encourage them to use whatever opportunity available to learn about the disease. It might also affect their health seeking practices making them visit health facilities for treatment.

Most of the respondents said they would experience fear if told their children were infected with TB. In Sindh province, Pakistan, a study was done to assess knowledge, attitudes and practices focusing on gender perspectives. From the study TB was feared (Hoa et al., 2009). Most mothers in Kapsabet Referral Hospital would visit a health facility if they found out their children had signs and symptoms of TB. Some still would not because of fear which creates a negative attitude towards the disease. A study done in Eastern Amhara Regional State, Ethiopia found out that there was so much stigmatization and fear on personal and family TB status (Desale et al., 2013). As long as mothers have the fear of being associated with the disease, is enough reason for them not to visit a health facility for treatment of their children.

Mothers with higher levels of education, Christians and those with regular income compared to those with irregular or indefinite income were more likely to have positive attitudes towards pediatric TB. Reason might be that such mothers were more informed on the disease on matters to do with signs and symptoms of TB, prevention of transmission, effective sources of information and availability of specific drugs for treatment therefore less worried. Age of the mothers and number of children were statistically significant to overall attitudes towards pediatric TB. Being older and having had more children comes with more experiences which may affect an individuals' attitude towards a disease.

\subsection{Mothers' Health Seeking Practices Towards Pediatric TB}

Majority of mothers visiting MCH at Kapsabet Referral Hospital, Nandi County, Kenya would visit a health facility if they suspected their children had TB. Others would still see a pharmacist or a traditional healer. This is not similar to a study done on community's knowledge, attitudes and practices in Shinile town, Somali Regional State, Eastern Ethiopia where most of the participants preferred self-treatment (Tolossa et al., 2014). Results from this study show that education was statistically significant to health seeking practice. People with high levels of education can access TB treatment and care easily compared to other community members. This was according to a research done in Enugu, South East Nigeria. Most mothers in the study area had high school and higher education levels making it a contributing factor.

Some mothers gave their reasons for not visiting health facilities as cost and difficulties with transportation 
or distance to the clinic. According to (Cambanis et al., 2005), a research done to find out the relationship between poverty among remote dwellers and how it affects their timing on accessing tuberculosis services in Ethiopia, residency and transport are some of the factors leading to delays in health seeking practices in relation to tuberculosis ; those living in remote places were less likely to visit a health facility because of the long distances. Transport costs and having to travel at night were also contributors. This could be the reason why some mothers from Kapsabet Referral Hospital, said they would wait long before visiting a health facility. Some mentioned they would first try self-treatment by visiting a pharmacy while others would take their children to traditional healers.

\subsection{Association of Mothers' Pediatric TB Knowledge and Attitudes with Health Seeking Practices}

Mothers who knew cough that lasts longer than 3 weeks, weight loss, fever, chest pain, shortness of breath and ongoing fatigue were signs and symptoms of pediatric TB were more likely to take their children to a health facility. Considering this, it is clear that most of the participants had information on pulmonary TB and not non pulmonary TB. A study done on health care seeking delay among pulmonary tuberculosis in North West zone of Tigrai region, North Ethiopia revealed that knowledge among other factors was significantly associated with health practices of patients (Alema et al., 2019). Other symptoms like severe headache and chills were more likely to be confused for other diseases like malaria which is prevalent in the study area. Nausea was significantly associated with seeking health care in a health facility. This might be because nausea causes discomfort which might force one to seek health care immediately.

Mothers who knew there are specific drugs available in health centers for treatment of TB were significantly more likely to take their children to a health facility when infected with TB. This is consistent with a study on pulmonary TB where participants knew of available modern drugs (Bati et al., 2013). The reason could be the fact that these medications are only offered in a health facility and not in a pharmacy or by a traditional healer.

Having the opinion that anybody could be infected with TB and wanting to get more information on the disease was significantly associated with seeking health care in a health facility. This means that having a positive attitude towards pediatric TB encourages good health seeking practice. Also, on attitudes apart from "fear" answered by most respondents a few of them said 'shame' which was significantly associated with seeking health care from a pharmacy. One is likely to be seen by many when visiting a health facility as compared to a pharmacy and this could be the reason why some would prefer to see a pharmacist. This agrees with a study by (Paz-Soldan et al., 2014) which found out that some people would not like to be seen at TB clinics whether it is for individual diagnosis or for their children.

Considering overall level of knowledge and attitudes towards pediatric TB from the study, mothers with good knowledge and positive attitudes were more likely to seek health care in a health facility as compared to visiting a pharmacy or a traditional healer. This is more or less similar with other studies (Bacay-Domingo and Ong-Lim, 2009), (Mangesho et al., 2007), (Khan et al., 2006), (Qureshi et al., 2008).

\section{Conclusion}

Considering mothers' knowledge on pediatric TB, it is clear that respondents had some knowledge which can be considered inadequate. Some gaps still exist in that a majority of mothers did not know there are other signs like chills, ongoing fatigue, loss of appetite, night sweats, nausea and severe headache that can also be associated with pediatric TB. Also, on prevention a smaller percentage answered vaccination since most of them did not associate $\mathrm{BCG}$ vaccine with TB.

With reference to attitudes, despite the mean showing a general negative attitude, it is encouraging because a slight majority of mothers had positive attitudes. Also, on health seeking practices most of the mothers said they would visit a health facility for treatment of their children. Others still would engage in risky health practices like going to a pharmacy or visiting a traditional healer. The fourth objective showed that there was an association of pediatric TB knowledge and attitudes with health seeking practices in Kapsabet Referral Hospital, Nandi County, Kenya.

Findings from the study calls for health administrators and policy makers to come up with measures that would significantly reduce pediatric TB morbidity and mortality in the study area. To start with, health education interventions focused on pediatric TB knowledge and attitudes and its translation to good practices are needed. Results from the study show that mother's age, level of education, religion, source of income and number of children are some of the important factors that need to be considered when coming up with community-based interventions to control TB.

There is also a need to strengthen pediatric TB education through radio and health workers which seem to be effective information dissemination tools. The national TB control program can use these means to coordinate advocacy, communication and organize social mobilization activities. This will lead to better knowledge, attitude and health seeking practices among mothers and the public in general.

Since this study was carried out in one locality, further studies in different areas with larger samples is encouraged. In some KAP factors the association was not significant so a further evaluation on this is required. 


\section{Acknowledgements}

We acknowledge the University of Eastern Africa, Baraton for providing logistic support required to carry out this study. We also acknowledge Kenyan National Commission for Science, Technology and Innovation and Kapsabet Referral Hospital for allowing us to do research in a health facility in the country. Most of all we acknowledge mothers who gave consent and participated as respondents in the study.

\section{References}

Alema, H.B., Hailemariam, S.A., Misgina, K.H., Weldu, M.G., Gebregergis, Y.S., Mekonen, G.K., Gebremedhin, K.A., 2019. Health care seeking delay among pulmonary tuberculosis patients in North West zone of Tigrai region, North Ethiopia. BMC Infect. Dis. 19, 309. https://doi.org/10.1186/s12879-019-3893-7

Bacay-Domingo, M.C.N., Ong-Lim, A.L., 2009. A Descriptive Study of the Knowledge, Attitudes and Practices on Tuberculosis among Treatment Partners of Pediatric Patients in Tarlac City. Pediatr. Infect. Dis. Soc. Philipp. J. 10, 28-34.

Bati, J., Legesse, M., Medhin, G., 2013. Community's knowledge, attitudes and practices about tuberculosis in Itang Special District, Gambella Region, South Western Ethiopia. BMC Public Health 13, 734. https://doi.org/10.1186/1471-2458-13-734

Cambanis, A., Yassin, M.A., Ramsay, A., Squire, S.B., Arbide, I., Cuevas, L.E., 2005. Rural poverty and delayed presentation to tuberculosis services in Ethiopia. Trop. Med. Int. Health 10, 330-335. https://doi.org/10.1111/j.1365-3156.2005.01393.x

Desale, A., Ali, I., Esmael, A., Yaregal, Z., Desta, K., Agonafir, M., 2013. Assessment of Patients' Knowledge, Attitude, and Practice Regarding Pulmonary Tuberculosis in Eastern Amhara Regional State, Ethiopia: CrossSectional Study. Am. J. Trop. Med. Hyg. 88, 785-788. https://doi.org/10.4269/ajtmh.12-0312

Desalu, O.O., Adeoti, A.O., Fadeyi, A., Salami, A.K., Fawibe, A.E., Oyedepo, O.O., 2013. Awareness of the Warning Signs, Risk Factors, and Treatment for Tuberculosis among Urban Nigerians. Tuberc. Res. Treat. 2013, 5. https://doi.org/10.1155/2013/369717

ECONOMIC SURVEY 2013, 2017. . Kenya Natl. Bur. Stat. URL https://www.knbs.or.ke/download/economicsurvey-2013/ (accessed 3.1.19).

Hoa, N.P., Chuc, N.T.K., Thorson, A., 2009. Knowledge, attitudes, and practices about tuberculosis and choice of communication channels in a rural community in Vietnam. Health Policy 90, 8-12. https://doi.org/10.1016/j.healthpol.2008.08.006

Khan, J., Irfan, M., Zaki, A., Beg, M., Hussain, S., Rizvi, N., 2006. Knowledge, attitude and misconceptions regarding tuberculosis in Pakistani patients. J. Pak. Med. Assoc. 211-214.

Mangesho, P., Shayo, H., Elizabeth, Makunde, W., B S Keto, G., I Mandara, C., Kamugisha, M., Kilale, A., Ishengoma, D., 2007. Commnity Knowledge, Attitudes and Practices Towards Tuberculosis and Its Treatment in Mpwapwa District, central Tanzania. Tanzan. Health Res. Bull. 9, 38-43.

Mungai, B., 2017. Kenya Tuberculosis Prevalence Survey - Brenda Mungai.pdf [WWW Document]. URL http://kenyapaediatric.org/resources/conference17/presentations/Tuberculosis/Kenya\%20Tuberculosis\%20P revalence\%20Survey\%20-\%20Brenda\%20Mungai.pdf (accessed 3.7.19).

National Tuberculosis, Leprosy and Lung Disease Program, 2017. Annual Reports - National Tuberculosis, Leprosy and Lung Disease Program. URL https://www.nltp.co.ke/annual-reports/ (accessed 6.7.19).

Paz-Soldan, V.A., Alban, R.E., Dimos Jones, C., Powell, A.R., Oberhelman, R.A., 2014. Patient Reported Delays in Seeking Treatment for Tuberculosis among Adult and Pediatric TB Patients and TB Patients Co-Infected with HIV in Lima, Peru: A Qualitative Study. Front. Public Health 2. https://doi.org/10.3389/fpubh.2014.00281

Qureshi, S.A., Morkve, O., Mustafa, T., 2008. Patient and health system delays: Health-care seeking behaviour among pulmonary tuberculosis patients in Pakistan. J Pak Med Assoc 58, 5.

Roy, A., Eisenhut, M., Harris, R.J., Rodrigues, L.C., Sridhar, S., Habermann, S., Snell, L., Mangtani, P., Adetifa, I., Lalvani, A., Abubakar, I., 2014. Effect of BCG vaccination against Mycobacterium tuberculosis infection in children: systematic review and meta-analysis. BMJ 349, g4643. https://doi.org/10.1136/bmj.g4643

Tolossa, D., Medhin, G., Legesse, M., 2014. Community knowledge, attitude, and practices towards tuberculosis in Shinile town, Somali regional state, eastern Ethiopia: a cross-sectional study. BMC Public Health 14, 804. https://doi.org/10.1186/1471-2458-14-804

World Health Organization, 2018. Global tuberculosis report 2018. 